\title{
Pixadores pela cidade: (i)legalidades e ambi- guidades nas extensas relações da pixação de Belo Horizonte
}

\author{
Rodrigo Amaro de Carvalho ${ }^{1}$ \\ Universidade Federal do Rio de Janeiro, Rio de Janeiro, Rio de Janeiro, Brasil
}

Dol: $10.11606 /$ issn.2316-9133.v22i22p225-237

resumo $\mathrm{O}$ presente artigo objetiva apresentar parte dos resultados finais da minha dissertação de mestrado, que consistiu em estabelecer uma etnografia com os pixadores da cidade de Belo Horizonte (CARVALHO, 2013). A partir da observaçâo participante, em meio à prática e aos espaços de encontro dos pixadores e, da análise de diversificadas fontes de pesquisa é que conseguimos investigar as estratégias (i)legais utilizadas pelos Policiais Militares e pelo Poder Público para inibir e punir as açôes dos pixadores. Assim, conseguimos etnografar algumas formas de violência policial, bem como as estratégias utilizadas pelos pixadores para resistir e burlar estes mecanismos coercitivos. Inúmeros foram os comentários e as representaçôes negativas por mim mapeadas, desferidas pelos pixadores contra as diversas esferas de atuação do poder público. Em suma, apresentaremos como a repressão age de modo retroativo, isto é, reprimindo, mas também contribuindo para a prática da pixação.

palavras-chave Pixadores; Policiais; (I)legalidades; Relações; Belo Horizonte

Pixadores in the city: (i)legalities and ambiguities in the extensive relationships of pixação in Belo Horizonte

abstract This article presents part of my Master's thesis final results, which consisted in establishing an ethnography with taggers in the city of Belo
Horizonte (CARVALHO, 2013). From participant observation on the practice and meeting spaces of taggers and the analysis of diverse sources of research, we can investigate the (il)legal strategies used by the Military Police and the Government to inhibit and punish the actions of taggers. Thus, we ethnography some forms of police violence, as well as the strategies used by these taggers to resist and to circumvent these coercive mechanisms. Were numerous comments and negative representations, mapped by me, directed by these taggers against the various spheres of governmental activity. In short, we present that the repression acts retroactively, which means, repressing but also contributing to the practice of tagging.

keywords Taggers; Police; (Il)legalities; Relations; Belo Horizonte.

\section{Apresentação preliminar da pixação de Belo Horizonte}

À primeira impressão, a pixação ${ }^{2}$ pode parecer, para um transeunte desavisado, um fenômeno simples e homogêneo, mas, ao analisá-la com certa acuidade, percebemos que ela configura um todo complexo e diversificado de práticas simbólicas e significaçôes, possuindo também peculiaridades em suas formas de socialidade. Em busca de adrenalina, reconhecimento e, às vezes, como forma de protesto, seus praticantes se arriscam em meio à paisagem da metrópole. Estas motivaçôes, de um modo geral, são as mais frequentemente citadas 
nas entrevistas concedidas pelos pixadores, seja naquelas efetivadas ao longo desta etnografia, seja em documentários, revistas especializadas e, também, nas redes sociais.

Diferentes são as formas de intervenções e apropriaçóes que os pixadores estabelecem com a paisagem urbana. Contudo, valoriza-se a busca pelo maior número de inscrições, independentemente da natureza do suporte de que o autor está se apropriando em meio à cidade. No entanto, vale lembrar que quanto maior a dificuldade demandada pelos fatores limitantes da ação do pixador, tais como, sistemas de segurança privados, cercas elétricas, altura do prédio escalado, proximidade e patrulhamento da polícia, dentre outros, maior será o seu reconhecimento em meio aos pixadores da sua galera, bem como dentre as outras galeras de pixação - maior será o seu ibope.
Por se tratar de um tipo de escrita de difícil leitura, podemos inferir, de um modo geral, que a pixação de Belo Horizonte caracteriza-se como um estilo de comunicação fechada, uma vez que os pixadores, embora acabem também chamando a atenção da sociedade, pretendem se comunicar, na maioria das vezes, apenas com outros pixadores. Neste sentido, em função da dificuldade em ler as inscriçôes grafadas nos distintos suportes, podemos concluir que a fama e o reconhecimento, ou ibope, utilizando os termos do vocabulário da pixação, tão presentes nas falas das entrevistas destes agentes, se restringem ao reconhecimento de seus pares. ${ }^{3}$ Assim, a pixação, de certo modo, caracteriza uma forma de escrita e comunicação restrita a quem compartilha dos seus códigos e símbolos culturais, somente sendo compreendida pelos atores que fazem parte deste circuito (MAGNANI, 2007).

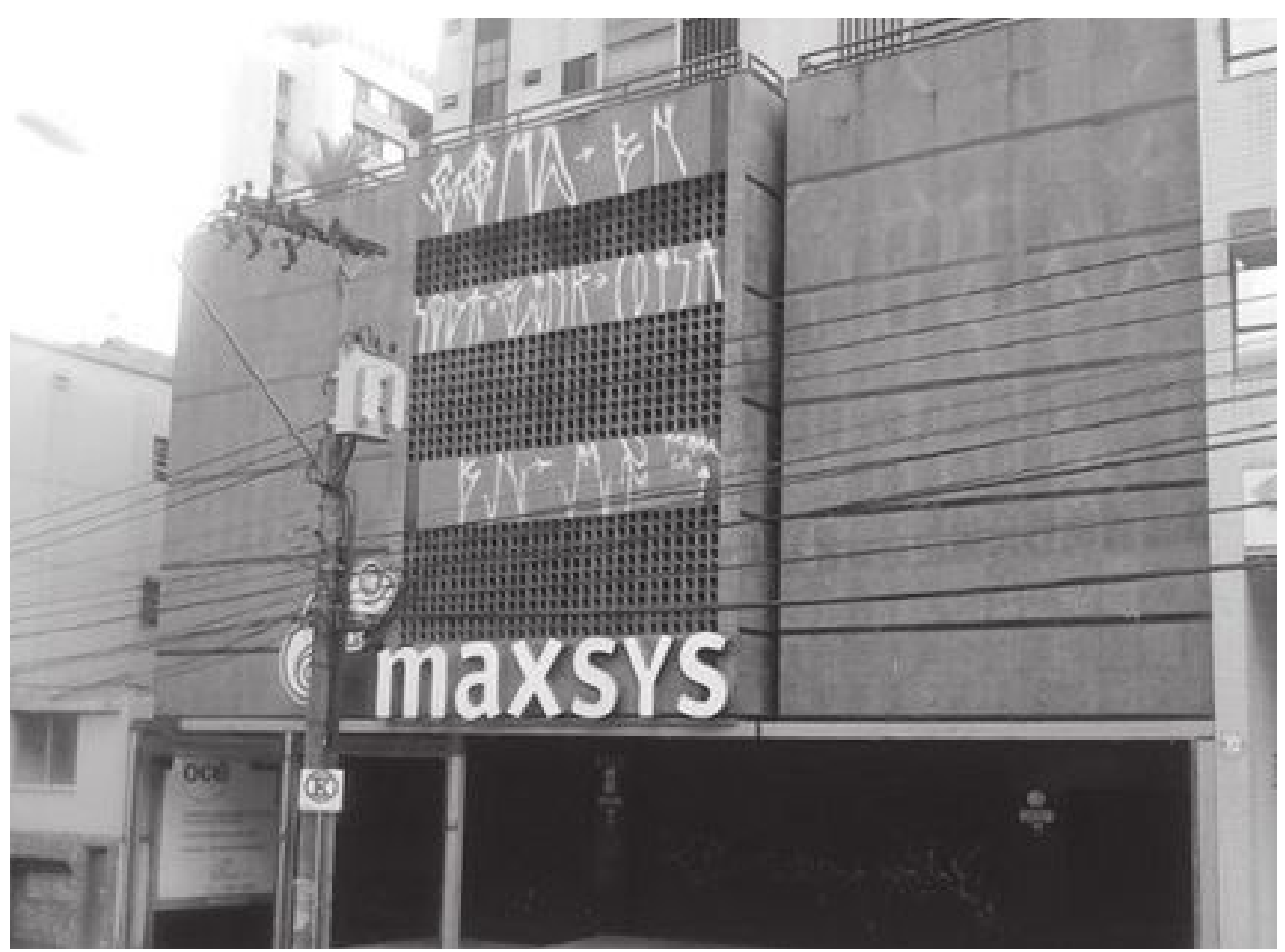

GOMA, SODA, GINK, COISA. BN e MF. (Créditos da Imagem: Rodrigo Amaro) 
As marcas grafadas pelos jovens em meio à metrópole, em sua grande maioria, contêm o vulgo que identifica o autor - neste caso, designado pela categoria nativa preza -, somado com o nome do grupo ou coletivo, conhecido pela expressão galera, e em algumas vezes fazem alusão também à região onde está localizado o bairro onde o agente reside. Em alguns casos também os agentes ainda escrevem frases que podem variar, grosso modo, entre um breve relato da intervenção ou, simplesmente, frases que contenham alguns lemas famosos entre os pixadores, envolvendo temas como relacionalidades, polícia, ibope, trechos de letras de Rap, protestos, dentre outros. ${ }^{4}$

$\mathrm{Na}$ imagem destacada acima, na parte mais baixa, temos as inscrições com os nomes abreviados das duas galeras que estavam presentes no rolê, quais sejam, a BN (Banca Nervosa) e a MF (Malucos do Floresta). Já na parte intermediária que compóem o suporte em questão, observamos as prezas dos pixadores SODA GINK e COISA. Por fim, a parte superior foi preenchida pela inscrição do pixador GOMA - BN. Além das prezas e das siglas das galeras, ainda podemos observar no interior da letra $\mathrm{O}$ que compóe a preza GOMA uma letra $\mathrm{P}$ que, ao serem conjugadas, resulta no símbolo da grife Os Piores. Além disso, é importante salientar ainda que a sigla OP remete a uma aliança e a uma extensão da grife Os Piores de Sáo Paulo na capital mineira - diferentemente da grife Os Piores de Belô, que traduz uma união entre galeras/pixadores de Belo Horizonte.

A partir das categorias nativas atropelar, atravessar e quebrar - bem como por meio das histórias apresentadas por meio da interpretação e descrição de inúmeras imagens - podemos perceber como são importantes as relações estabelecidas entre os pixadores. Por conta disso, sigo aqui as contribuiçóes de Alfred Gell que, na obra Art and Agency, denuncia o falso problema existente no hábito de se tentar eluci- dar sistemas estéticos não ocidentais, refletindo sobre questóes relativas ao uso e aplicaçóes de conceitos próprios ao ocidente a contextos distintos. Assim, para Gell uma verdadeira Antropologia da Arte se define como o estudo teórico

das relaçóes sociais na vizinhança dos objetos que atuam como mediadores da agência social e propus que, para que a antropologia da arte seja especificamente antropológica, ela tem que partir da ideia de que, sob os aspectos teóricos relevantes, os objetos de arte equivalem a pessoas, ou, mais precisamente, a agentes sociais (GELL, [1998] 2009, p. 253).

Neste sentido, ao invés de me atentar para a questão que polemiza o fato da pixação ser ou não arte, nos parece aqui ser mais interessante investigar a dimensão relacional que tal fenômeno comporta. Portanto, a partir de um projeto antropológico, com inspirações claramente maussianas, Gell propõe que a teoria antropológica da arte é a teoria da arte que "considera os objetos de arte como pessoas" (GELL, [1998] 2009, p. 255).

Dito isto, podemos concluir que o circuito da pixação deve ser visto tal como um mosaico, dotado de características e significações próprias e heterogêneas, possuindo uma dinâmica própria que se relaciona de forma estreita com os fatores relacionados com as próprias regras do espaço urbano. Assim, os pixadores estabelecem novas formas de apropriação e significação da urbe a partir dos seus próprios códigos simbólicos e de suas próprias formas de socialidades.

\section{Quando a pixaçáo está para além dos muros: as ambíguas e extensas relaçóes dos pixadores mineiros}

No ano de 2010, em específico, no mês de novembro, um acontecimento colocou o fenô- 
meno da pixação em foco em Belo Horizonte, qual seja, o flagrante de cinco jovens em um prédio da região central, seguido da prisão e enquadramento dos mesmos por crime de formação de quadrilha. ${ }^{5}$ Tal acontecimento teve grande repercussão na mídia, especialmente, na mídia eletrônica. Ao investigar as opinióes referentes à prisão dos pixadores percebemos uma gama diversificada de juízos, se estes deveriam ou não ser enquadrados como formação de quadrilha, ou se estes deveriam ser punidos apenas pela prática da pixação. De todo modo, quando o assunto é pixação, predominantemente, nos deparamos com apreciaçóes que relegam os pixadores às categorias de vândalos e criminosos.

Dito isto, vale lembrar que, conforme Howard Becker, "todos os grupos sociais fazem regras e tentam, em certos momentos e em algumas circunstâncias, impô-las”. As regras sociais "definem situaçóes e tipos de comportamento a elas apropriados, especificando algumas ações como 'certas' e proibindo outras como 'erradas'” (BECKER, 2008, p. 15). ${ }^{6}$

A pixação, juntamente com as outras modalidades de inscriçóes urbanas, na maioria das vezes póe frente a frente diferentes grupos sociais, na medida em que coloca em discussão a questão paradigmática da propriedade privada, bem como a liberdade de expressão. Clifford Geertz (1994) destaca que, de acordo com a perspectiva funcionalista, as "obras de arte são mecanismos elaborados para definir as relaçóes sociais, manter as regras sociais e fortalecer os valores sociais" (p. 150). Nesse sentido, ao invés de corroborar para com as regras e valores sociais, estas práticas "apenas materializam uma forma de viver, e trazem um modelo específico de pensar para o mundo dos objetos, tornando-o visível" (Ibidem). Percebemos que esta forma de intervenção pôe em discussão, dentre outras problemáticas, sobretudo, o estatuto da propriedade privada, uma vez que o pixador se apropria da propriedade alheia para efetuar suas açōes.

Com o intuito de combater a pixação, a Prefeitura de Belo Horizonte, na atual gestão do Prefeito Marcio Lacerda, declarou guerra às açóes dos pixadores. Juntamente com a PBH, o Poder Judiciário, a partir do cumprimento de inúmeros mandatos de busca e apreensão, também vem atuando de forma bastante incisiva contra os pixadores mais atuantes de Belo Horizonte. $^{7}$ Além disso, a PBH também combate a pixação estabelecendo uma guerra de tinta contra os pixadores, através do fomento de programas como o Movimento Respeito por $\mathrm{BH}$, que tem por objetivo cobrir todas as pixaçóes encontradas pelos agentes da prefeitura e por voluntários nas ruas da capital mineira. ${ }^{8}$ Resumidamente, os objetivos do programa supracitado são definidos da seguinte maneira:

O Movimento Respeito por $\mathrm{BH}$ visa garantir o ordenamento e a correta utilizaçấo do espaço urbano pelo cumprimento e efetiva aplicação da legislação vigente. Visando intervir de forma efetiva, pautada pela legislação vigente e preservando os códigos de convivência urbana, foram traçadas três estratégias integradas para combater a pichaçấo e que podem ser executadas de forma independente: REPRESSÃO QUALIFICADA, SENSIBILIZAÇÃO e DESPICHE.?

A prefeitura da metrópole mineira investe muitos recursos financeiros e materiais para monitorar a cidade por meio de programas e sistemas de segurança. Do mesmo modo que o Poder Judiciário, a Polícia Militar, por meio do programa de monitoramento conhecido como "Olho Vivo" intenta inibir a ação dos pixadores nas principais vias da cidade. Além disso, mapeamos um esforço conjunto entre a iniciativa privada e a iniciativa pública, que através de três diretrizes de ação, planejadas pelo programa 
Movimento Respeito por BH, visa, igualmente combater a pixação na capital mineira.

Neste ponto, nos interessa abordar a segunda diretriz de ação do programa citado, a saber, a esfera de atuação intitulada por seus idealizadores como "sensibilização". Nesse sentido, a SMED - Secretária Municipal de Educação de Belo Horizonte - intenta redirecionar o foco e a "energia dos jovens da pichação para atividades de caráter cultural e de responsabilidade socioambiental." Para tanto, muitas das vezes, o grafite é acionado como um vetor de combate à pixação. Tal estratégia fica patente em uma matéria divulgada no site da emissora Alterosa, que começa com a seguinte analise: "Uma matemática vergonhosa. Trezentas novas pichaçóes aparecem todos os meses em Belo Horizonte, segundo a Polícia Militar”. Mas o que mais nos interessa na referida matéria é a alternativa encontrada pelos moradores do Bairro Horto. Eles deram lugar nos muros à arte. A frente da serralheria de Geraldo Galinari ficou mais bonita com o grafite. "Aqui é pintar uma parede nova e eles picham mesmo, com o grafite eles respeitam." 10

Investigando outras pesquisas que tratam desta questão, percebemos que esta estratégia é largamente utilizada. Em São Paulo, Alexandre Pereira aponta que

ocorre, então, um fenômeno interessante: a pixação, indiretamente, impulsiona a proliferaçấo de um agente de sua própria coerção, ou seja, o grafite. No entanto, é preciso problematizar essa oposição entre pixação e grafite e entre pixadores e grafiteiros (PEREIRA, 2007, p. 226).

Retomando a gênese histórica da pixação e do grafite, vimos que as histórias de ambas as práticas remetem a uma gênese comum. Visando combater a pixação, podemos perceber que o poder público, juntamente com a esfera privada, coloca e trata estas práticas de forma dicotômica. Contudo, a partir dos dados da pesquisa é possível afirmar que os limites entre estas práticas são muito fluidos. ${ }^{11}$ Por outro lado, é importante destacar que, mesmo sendo fluidos os limites entre tais práticas, existem conflitos entre os agentes destas manifestaçóes, principalmente, por conta dos atropelos. Corriqueiramente ocorrem atropelos de grafites que acabam por sobrepor pixações, ou, até mesmo, outros grafites. Com o

o grafite tornando-se uma das estratégias oficiais de combate à pixaçáo, muitos grafiteiros começaram a "atropelar" pixaçóes, o que provocou a indignação de muitos pixadores (PEREIRA, 2007, p. 229).

A este respeito o pixador PAVOR aponta que "grafite é bacana, são uns caras bem talentosos. Mas muitos deles são unidos com o sistema. E quem é unido com o sistema, nóis tamo contra”. Conscientes das estratégias de cooptação por parte do Poder Público, que tem por objetivo arrebanhar grafiteiros em prol de uma guerra de tinta tácita que ocorre pela cidade, onde o grafiteiro é eleito como um vetor de combate à pixação, é que, então, os pixadores começaram a devolver os atropelos sofridos nesta tentativa de higienização da capital mineira. Além do programa de combate à pixação citado anteriormente, em especial, temos em Belo Horizonte também o Projeto Guernica. ${ }^{12}$

Um ponto interessante que observei em alguns muros da cidade, que diz respeito às relaçóes estabelecidas pelos pixadores com a cidade como um todo e as tentativas de combate à pixação, se refere à prática dos moradores colocarem placas com dizeres que buscam negociar e apresentar razóes para os pixadores não pixarem seus muros. Neste sentido, buscando alternativas para a ineficaz repressão e 
combate estabelecido pelos órgãos públicos, moradores e construtoras se comunicam através dos próprios muros.

Atenção Sr. Pixador, a cada mês que esse muro permanecer limpo, a MRV e a Magis doarão uma cesta básica para uma creche ou uma instituiçẫo de caridade da sua cidade.

No entanto, a despeito da estratégia salientada anteriormente, os pixadores pixam os muros destes locais e, ainda, zombam dos mesmos. Assim, o pixador DATE marcou sua alcunha e deixou a seguinte frase em letras legíveis: "esse mês a cesta é por minha conta”.

Segundo a perspectiva dos próprios pixadores, a pixação é uma atividade ilícita, podendo ser caracterizada, portanto, como uma forma de delito criminal. Conforme a fala do pixador COISA, que argumenta que "a partir do momento que você está pixando um patrimônio que não é seu, subindo em casas e prédios, está fazendo uma coisa errada". No mesmo sentido, transcendendo os limites da capital mineira, o pixador paulistano CRIPTA reconhece a ilegalidade e o caráter de vandalismo presentes nas práticas exercidas pelos pixadores ao afirmar que a "pixação é ilegal mesmo, e a essência tá nisso cara. Se fosse autorizada, ninguém tava fazendo. A essência tá aí, na anarquia, tá ligado? Um bagulho proibido."13 Dessa maneira, notamos que os próprios agentes da pixação admitem que a pixação é uma intervenção subversiva, e que suas atividades, se julgadas perante as regras normativas da sociedade, são práticas ilegais, na medida em que os próprios reconhecem que se apropriam da propriedade alheia.

Entretanto, embora reconheçam o caráter desviante de suas açóes mediante as regras da sociedade, sabemos que, de acordo com Howard Becker (2008), a "sociedade em geral tem muitos grupos, cada qual com seu próprio con- junto de regras, e as pessoas pertencem a muitos grupos ao mesmo tempo" (p. 21). Podemos inferir que o pixador, como qualquer indivíduo, por participar de diversos grupos, acaba por "infringir as regras de um grupo pelo próprio fato de se ater às regras de outro" (Ibidem), neste caso, as próprias regras da pixação. Neste intenso e complexo jogo de classificaçôes, os policiais e os guardas municipais figuram de forma extremamente negativa na representação dos pixadores, sendo considerados como os seus principais adversários. Além desses personagens, os pixadores utilizam-se da expressão herói que se refere a moradores, transeuntes e vigias particulares que assumem o papel do Estado, e de alguma forma tentam inibir suas açóes. Assim, as categorias nativas porcos, vermes e gambés, se referem pejorativamente aos policiais militares, civis e guardas municipais.

No outro pólo da discussão, o Jornal Estado de Minas, em sua versão online, traz a seguinte matéria: "Mais de 100 pichadores já foram presos desde janeiro em BH":

\begin{abstract}
Moradores de Belo Horizonte que tiveram fachadas e muros de seus imóveis emporcalhados por pichadores podem comemorar uma estatística levantada pela Guarda Municipal e repassada ao Estado de Minas com exclusividade: de janeiro a novembro, a corporação prendeu 114 deles em flagrante. Alguns são tão audaciosos que foram detidos quando sujavam a sede da prefeitura, na Avenida Afonso Pena, no Centro, e o prédio da própria Guarda Municipal, na Avenida dos Andradas, mas os alvos prediletos dos vândalos são os monumentos erguidos em pontos estratégicos, como o obelisco da Praça Sete.
\end{abstract}

Em resumo, percebemos que ao classificar a açáo dos pixadores como sendo um ato praticado por vândalos, os jornalistas somente levam em conta o conteúdo das regras normativas de nossa 
sociedade em seus julgamentos acerca das açóes estabelecidas pelos pixadores, se privando de problematizar a perspectiva dos pixadores. Sendo assim, na medida em que o objetivo é "vender jornal", os jornalistas, na busca de satisfazer o anseio da grande maioria dos seus leitores, apelam para o desejo de ver os pixadores reprimidos.

Já o portal de notícias G1 traz a matéria intitulada: "Governo proíbe venda de tinta spray para menores de 18 anos". Assim, o tópico em destaque assinala que a partir da quinta-feira (26/05/2011), no Diário Oficial da Uniāo a Lei 12.408 , está proibida a comercialização de tintas em embalagens aerosol a menores de 18 anos. Pela lei, sancionada pela presidente Dilma Roussef,

a venda de spray em tinta só poderá ser feita a maiores de idade, mediante apresentação de documento de identidade. $\mathrm{O}$ texto obriga o comerciante a colocar na nota fiscal de venda a identificaçáo do comprador. As embalagens terão que conter, de forma legível e destacada, a seguinte expressão: "Pichação é crime" (Art. 65 da Lei no 9.605/98). "Proibida a venda para menores de 18 anos".

No comentário de outra matéria, um determinado leitor exprime sua insatisfação para com as atividades estabelecidas pelos pixadores e também para com as açóes punitivas, afirmando que a

polícia não prende por incompetência e com isso gera a impunidade. Emporcalham a cidade e não acontece nada. Os pichadores são uns frustrados, fracassados e sem perspectiva de futuro.

Nota-se na fala do leitor que a pixação, e, também, de um modo geral, é vista a partir da negativa, ou seja, sempre como uma falta, como resultado de uma assimetria de acesso à determinadas oportunidades. No texto intitu- lado "Somos todos grupelhos", Félix Guattari (1981) aponta que a problemática em torno das gangues possibilita examinar melhor o problema de onde partir para definir uma possível "subcultura", permitindo colocar em dúvida esse lugar social em relação ao qual fosse sempre necessário medir quaisquer outras manifestaçôes ou estilos. Ademais, Janice Caiafa, inspirada pelos escritos do mesmo, aponta, também, que

quanto às gangues, marginalidade é uma má palavra, pois implica sempre a ideia de uma dependência secreta da sociedade pretensamente normal. A marginalidade chama o recentramento, a recuperação. Vê-las não como uma periferia em relação a um centro, momentos dialéticos no discurso imperial, peripécias no percurso que seguem o Império e sua ideia (CAIAFA, 1987, p. 62).

Percebemos o conteúdo estigmatizante lançado sobre os pixadores pelos leitores e agentes da esfera pública - e também pela Sociologia e pela Antropologia que os vê como marginais, conforme Caiafa (1987).

Erving Goffman define estigmatização como uma forma de classificação social pela qual um "grupo identifica outro de acordo com certos predicados seletivamente reconhecidos pelo indivíduo classificante como pejorativos ou desabonadores" (GOFFMAN, 1988, p. 6667). Constantemente, encontramos na fala dos cidadãos as categorias "vândalos", "criminosos", dentre outras - termos que identificam a pixação com a destruição e com a sujeira, como em um determinado trecho anteriormente destacado. Em síntese, o pixador RALADO DC (Distúrbio do Crime) assinala que:

Belo Horizonte tá sendo motivo de piada no mundo. Cria disque denúncia pra pixadores, re- 
gistra fotos pra investigação [para] depois condenar e nos dar prisão. Tudo pra deixar a cidade bonita pro estrangeiro. Agora pergunta pro estrangeiro o que vê de feio no Brasil, pra ver a resposta dele. Nunca vai abrir a boca pra falar das pixaçôes da cidade, e se falar pode ter certeza que antes disso ele abriu a boca pra falar de corrupção, descaso com a saúde, miséria e mil e um problemas da cidade. Aí depois ele vai falar sobre a pixação!!! O pixo nunca vai acabar!

De tal modo, a partir da fala do pixador, notamos que este reconhece o estigma projetado pela sociedade sobre os pixadores. No entanto, ao nos reportarmos à sua fala, percebemos também que ele considera outros agentes como desviantes (BECKER, 2008, p. 15). Além disso, a partir da fala de RALADO DC, podemos inferir que os pixadores reconhecem o caráter desviante envolvido na prática da pixação, contudo definem e fundamentam suas condutas, mormente, com base nos atos transgressivos de outros grupos, neste caso, os políticos.

Ao problematizarmos as entrevistas destacadas anteriormente e ao analisarmos a preocupaçáo legal em conjunto com a criaçáo de mecanismos de combate à prática da pixação, percebe-se que a todo o momento entra em voga o debate acerca do desvio e, nesse sentido, abre-se um leque ainda mais amplo relativo ao entendimento deste fenômeno (SOUZA, 2008, p. 79). Segundo Becker, desvio pode ser definido como a "infração de alguma regra geralmente aceita", ou ainda, o termo utilizado para designar "pessoas que são consideradas desviantes por outras, situando-se por isso fora do círculo dos membros 'normais do grupo"” (BECKER, 2008, p. 21-27).

Para cumprir o objetivo do presente artigo destacarei alguns dados de campo, retirados de uma filmagem feita em uma das minhas observaçôes participantes da prática da pixa- ção. Em uma determinada madrugada, em uma das açóes do grupo que acompanhei, ocorreu um flagrante. Enquanto o pixador FAIN escalava uma das janelas e marcava a sua preza no segundo andar de um prédio, na Zona Norte de Belo Horizonte, foi notado por uma moradora, que prontamente começou a gritar: "pega ladrão, pega ladrão". As declaraçóes por parte da vizinha irritou muito os três integrantes da galera em questão. GINK: “Nóis volta ainda FAIN”. FAIN: 'É, 'nóis' volta ainda Zé. Deixa esse restinho do Jet pra mim”. GINK: "Nossa Zé, os caras 'gritou' ladrão, você viu?" FAIN: "É, os caras gritou ladrão. O cara da janela do GINK apareceu”.

A partir desse pequeno dado de campo, fiquei intrigado na busca de tentar compreender como funciona a noção própria de ética dos pixadores, pois estes, apesar de reconhecerem ou de estarem conscientes de que a pixação constitui uma prática desviante aos olhos da sociedade, se sentiram muito ofendidos pela moradora que os identificou com ladróes. Por conta do flagrante, FAIN teve que saltar do segundo andar, e veio correndo em direção ao carro, juntamente com GINK. Nesse momento, eu estava sentado no banco de trás do carro, e rapidamente, abri as portas para que os rapazes pudessem entrar. Assim que os jovens adentraram, COISA arrancou e deu fuga sentido Zona Leste. Durante a fuga, os jovens ficaram bastante apreensivos, pois, além de termos passado em alta velocidade em frente à Delegacia de Polícia Civil do bairro da Lagoinha, FAIN estava muito nervoso com um carro que vinha atrás: "Espera aí. Nossa, ao carro ali. Vamos sair fora daquele carro. Sai fora daquele carro, sai fora daquele carro que está vindo ali. Vai para o outro lado. Engole os bicos e os flagrantes".

A prática de se retirar e, posteriormente, engolir o bico, jogá-lo fora, ou ainda escondê-lo da vista dos Policiais é comum entre os 
pixadores. Tal estratégia é exercida com o intuito de não serem pintados pelos Policiais Militares, pois ouvi muitos relatos por parte dos pixadores contando que ao serem flagrados pelos PM's foram pixados pelos mesmos. Sem o bico na lata, o Policial fica impedido de praticar essa ação agressiva contra o pixador, uma vez que o pixador deu fim no mecanismo que ao ser acoplado e acionado ao spray é responsável pela emissão do jato de tinta.

Ainda sobre esta prática, GINK relatou que, em certa feita, ao ser pego pelos Policiais Militares, em uma cena nas margens da Av. Cristiano Machado, o PM responsável pela equipe que deu o flagrante, antes de tudo já disse: "se o bico não aparecer vai todo mundo para a Delegacia". Por conta disso, os rapazes mostraram para o policial militar aonde haviam jogados os bicos das latas e, assim, os PM's mandaram que os mesmos esticassem os braços que, consequentemente, foram pintados pelos mesmos. É importante destacar também que, apesar de ser um ato desviante praticado por vários policiais, ao longo da pesquisa, constatei que inúmeros pixadores preferem esse tipo de punição informal - e, em alguns depoimentos, até mesmo ser agredido - do que ir para a delegacia e ter que assinar o boletim de ocorrência. Prova disso é que GINK, sobre este episódio, relatou que, mesmo com o braço todo pintado em spray preto, se sentiu muito aliviado por não ter rodado e não precisar ir para a Deleg ${ }^{14}$.

Neste sentido, vale destacar que não há desvio em si, ou seja, o desviante não possui uma característica que o defina como tal, mas o que se percebe é a existência de um processo de acusação mútua, e o desviante passa a ser aquele que, por diferir das regras aceitas pela maioria da sociedade, acaba sendo qualificado dessa forma. Para Janice Caiafa, a perspectiva defendida por Howard Becker é relevante para estudos deste tipo, pois Becker soube desinvestir esses lugares sociais (os jovens, as mulheres e demais rebeldes, os "desviantes") de uma substância que os definiria desde o início. Eis seu esforço de contextualizar esses fenômenos, de enfatizar a situação, o processo pelo qual essas figuras se constituem - no que lhe interessa muito menos um afã classificatório do que o momento que propicia sua aparição (CAIAFA, 1987, p. 61).

Considerando as opiniôes antes destacadas, entendemos que, a partir da perspectiva dos pixadores entrevistados, estes estão conscientes do estigma projetado sobre eles. Desse modo, podemos caracterizá-los como o que Howard Becker chama de desviante puro, pois seus comportamentos, de um modo geral, podem ser entendidos como "aquele que desobedece à regra e é percebido como tal” (BECKER, 2008, p. 31). Ademais, muitas das vezes, percebe-se, nas entrevistas dos indivíduos que fazem parte dos setores que acusam os pixadores como desviantes, que a pixação não tem nenhuma serventia e nenhum sentido, ou que ela é apenas uma violência gratuita contra a sociedade, não tendo nenhuma finalidade prática. Entretanto, dentro deste universo multifacetado, que é a pixação, encontramos em nossa pesquisa determinadas galeras/pixadores que não encerram a pixação somente dentro de uma intervenção urbana apolítica e identitária. Sendo assim, a atitude de alguns grupos de pixadores em protesto contra casos, como, por exemplo, de violência e descaso da justiça, divide a opinião pública e cria novos conceitos para a pixação.

Destarte, por um lado, ao mesmo tempo em que a mídia veicula opinióes que relegam os pixadores às categorias estigmatizantes, tais como, as de criminosos e vândalos, também contribui para o fenômeno da pixação, pois os pixadores colecionam todas as matérias que são veiculadas na mídia impressa, na medida em 
que estar na imprensa ajuda a divulgar a sua alcunha individual e a sigla da sua galera, aumentando, consequentemente, o ibope da galera no meio da pixação. Concluímos também que a imagem de vândalos não os incomoda, e a imprensa em nada os pode prejudicar; pelo contrário, esta por mais que lhes atribua inúmeros qualificativos estigmatizantes, acaba por promover e retroalimentar o fenômeno da pixação. Ademais, vimos que as ambiguidades e (i) legalidades são inerentes e cambiantes dentre pixadores e policiais.

\section{"Rabiscando" algumas consideraçóes finais}

Podemos inferir que o estudo da prática da pixação em Belo Horizonte nos permite extrair duas conclusôes principais, mas que deixam entrever inúmeras outras constatações etnográficas mais pormenorizadas. Assim, dois temas perpassam todos os tópicos apresentados anteriormente, a saber: podemos perceber um "relacionismo radical" e um modo de conduta que se contrapóe à ordem vigente, que se efetiva por meio de distintas práticas, para além do simples ato de pixar. A meu ver, foi interessante constatar como a prática da pixação questiona valores como, por exemplo, o estatuto da propriedade privada, levando ao limite a problemática que tangencia o direito à liberdade de expressão. No entanto, ao mesmo tempo, tal fenômeno reproduz alguns valores caros à sociedade urbana contemporânea, tais como a disputa e a individualidade.

Como salientamos anteriormente, a ambiguidade parece ser uma característica marcante e inerente ao fenômeno sobre o qual nos debruçamos. Tal ambiguidade se mostra patente quando analisamos as falas dos pixadores que, ao mesmo tempo que criticam os órgáos res- ponsáveis pela inibição de tal fenômeno, advogam e defendem a importância do caráter ilegal da pixação. Inúmeros foram os comentários e as representaçóes negativas por mim mapeadas, desferidas pelos pixadores contra o "Olho Vivo”, a Polícia Militar, a Guarda Municipal e a $\mathrm{PBH}$. Todavia, como os mesmos ressaltam constantemente que boa parte da adrenalina proporcionada durante o rolê se dá pela ilegalidade, pelo perigo de ser flagrado por um gambé, podemos concluir que a repressão age de modo retroativo, logo, reprimindo, mas também contribuindo para a prática da pixação. Sendo assim, por mais que os pixadores critiquem os desvios de conduta por parte dos policiais, estes, em determinadas situaçóes, se sentem beneficiados quando os policiais não atuam dentro da lei.

Por meio desta abordagem mais ampla é que percebemos, portanto, como este fenômeno deve ser apreendido através das suas mais distintas formas de relação. Isto é, advogamos que para abordar um objeto de pesquisa como este, que pode ser visto como uma forma de desvio social, seja importante mapear, senão todas, a maior parte das relaçóes estabelecidas pelos pixadores, tais como podemos observar no esquema abaixo:

\begin{tabular}{|l|}
\hline pixadores $\mathrm{x}$ policiais militares \\
\hline pixadores $\mathrm{x}$ policiais civis \\
\hline pixadores $\mathrm{x}$ guarda municipal \\
\hline pixadores $\mathrm{x}$ PBH \\
\hline pixadores $\mathrm{x}$ publicidade \\
\hline pixadores $\mathrm{x}$ taxistas \\
\hline pixadores $\mathrm{x}$ vigilantes particulares \\
\hline pixadores $\mathrm{x}$ moradores \\
\hline pixadores $\mathrm{x}$ proprietários \\
\hline
\end{tabular}

Sendo assim, apreendemos o quão é extensa a rede de relaçóes, inexoravelmente, estabelecida, ainda que, por vezes, de forma indireta, 
pelos pixadores na Grande Belo Horizonte.

Pensando à luz de um dos contributos da antropóloga britânica Marylin Strathern, que afirma que as "as pessoas não interagem 'com' cultura, elas interagem com pessoas com quem têm relaçóes" (STRATHERN, 2005, p. 132), é que afirmamos que não existe uma cultura da pixação mineira em si, como uma realidade dada, ou como termo independente. Portanto, esta deve ser entendida dentro de um sistema que coloca em relação não só pessoas, mas um conjunto de coisas que possuem um poder de agência. Em suma, em todos os âmbitos que analisamos a pixação mineira, seja nas suas formas de apropriação e usos do espaço, seja na constituição dos nomes das galeras e grifes, em suas formas de produzir seus próprios produtos, ou ainda nas suas peculiares formas de apropriação da mídia, podemos perceber que há todo um modo de ser marginal, um discurso e uma prática que vão contra a ordem vigente, dentro de um complexo contexto relacional.

\section{Notas}

1. Doutorando do Programa de Pós-Graduação em Antropologia Social, Museu Nacional, UFRJ.

2. Conforme o Dicionário Aurélio, o termo pichação é resumido como "versos, em geral de caráter político, escrito em muro de via pública”. Por sua vez, o Dicionário Eletrônico Houaiss da língua portuguesa, define que pichar é "escrever ou rabiscar dizeres de qualquer espécie em muros, paredes ou fachadas de qualquer espécie". Diferentemente dos significados expressos por ambos os dicionários, a Pixação escrita com "x" náo carrega consigo o estigma social apontado pelos dicionários, bem como pelo senso comum. Sendo assim, de acordo com Alexandre Barbosa Pereira, em sua dissertação de Mestrado sobre os pixadores de São Paulo, "é assim que os pixadores escrevem e isso diferencia esta de outras formas de escrita na parede, portanto, de outras pichaçóes" (PEREIRA, 2005, p. 9). Assim, ao longo deste artigo, as categorias nativas serão apresentadas ao leitor em itálico. Já as categorias analíticas serão colocadas entre aspas.

3. Na maioria das vezes, os suportes são escolhidos levando em conta a expressão comum utilizada pelos meios midiáticos, qual seja, ibope. Tal expressão foi ressignificada pelos pixadores, e diz respeito à fama, reconhecimento e a repercussão das suas açōes e do próprio status do pixador entre seus pares.

4. As prezas, geralmente, variam entre três e cinco letras, podendo chegar a ter até seis letras. Uma preza com cinco letras já é considerada pelos pixadores como sendo uma preza grande. Neste sentido, a maioria das prezas contém quatro letras, pois as prezas menores são feitas em maior velocidade, permitindo que o pixador a faça sem gastar muito tempo, livrando-o de um possível flagrante por parte de um policial militar, vigilante ou por algum transeunte. Já a expressão grife, em linhas gerais, designa uma aliança entre pixadores de distintas galeras que se unem sob um único nome, somadas ao próprio codinome do autor que a inscreveu.

5. Para ver o mandato de busca e apreensão, na íntegra, acesse o seguinte endereço eletrônico: http://www.iob. com.br/noticiadb.asp?area $=$ juridicas\&noticia $=166003$.

6. O pixador pego em flagrante pode ser detido conforme a lei ambiental $n^{\circ} 9.605$ de 1998, que assinala que "pichar, grafitar ou, por outro meio, conspurcar edificação ou monumento urbano é crime passível de detenção de três meses a um ano e multa”. Ainda cabe lembrar que o ato de pixar também pode ser enquadrado no artigo 163, de acordo com o Código Penal, o qual prevê que "causar dano, destruir, inutilizar ou deteriorar coisa alheia constitui crime" (SOUZA, 2008, p. 81). Vale lembrar, ainda, que Becker distingue dois tipos distintos de regras: as formais, formalmente promulgadas na forma de lei; das regras que se baseiam em acordos, impostas por sançôes informais de diversos tipos. Neste sentido, a prática da pixação, perante a lei, configura uma atividade ilegal, uma vez que o pixador se apropria de locais públicos ou privados para efetivar suas intervençóes em meio à paisagem urbana. Sendo assim, as pixaçóes, geralmente, ocorrem durante a madrugada de forma sorrateira. Deste modo, podemos inferir que a subversão pode ser vista como uma de suas características principais, pois a pixação não é uma prática aceita ou normatizada pela sociedade.

7. A este respeito, destaco um trecho da fala do prefeito 
de Belo Horizonte, um dia após o resultado de sua reeleição: "Uma cidade da qualidade de Belo Horizonte não pode conviver com tanta pichação que nós temos nos imóveis pela cidade toda. Nós precisamos dar um basta, encontrar uma forma de resolver isso, que um desrespeito que acaba gerando outros tipos, digamos, de desrespeito às leis. Às vezes, a pichação é uma porta de entrada para uma gangue organizada. Depois vai para um pequeno furto, vai para um assalto, vai para as drogas e assim por diante. Nós temos um crescimento da criminalidade na cidade, e isso é inaceitável". A matéria com a entrevista completa pode ser acessada na íntegra no endereço eletrônico: http://g1.globo.com/minas-gerais/eleicoes/2012/noticia/2012/10/prefeito-de-bh-diz-que-e-cedo-para-relacionar-vitoria-e-eleicoes-de-2014.html.

8. Cabe lembrar que grande parte das capitais brasileiras, incluindo Belo Horizonte, conta com um sistema de disque denúncia para que a população, através do número 181 , ajude a polícia no intento de prender pixadores em flagrante.

9. O documento completo pode ser acessado no sítio: http://www.cidadedemocratica.org.br/topico/1847-movimento-respeito-por-bh-combate-a-pichacao.

10. A matéria completa pode ser acessada no sítio eletrônico: <http://eusr.wordpress.com/2011/11/25/ bh-gasta-r-2-milhoes-por-ano-para-limpar-a-cidade-da-sujeira-dos-pichadores/>.

11. Em determinados momentos, os pixadores, devido às dinâmicas das circunstâncias encontradas em suas práticas cotidianas, acionam diferentes categorias identitárias para, por exemplo, dialogarem com as autoridades responsáveis pelo combate à prática da pixação, assim como com outros agentes de um modo geral. Sendo assim, me deparei com inúmeros pixadores que fazem grafites e, também, com grafiteiros que fazem pixaçóes. Se abordarmos as relaçóes entre a pixação e o grapixo, veremos que as relaçóes são ainda mais fluidas entre estes agentes e práticas.

12. Tal projeto, grosso modo, é um programa da Prefeitura de Belo Horizonte, em parceria com o Centro Cultural UFMG e a FUNDEP, que desde o ano 2000 constitui um espaço de estudo e pesquisa, mas que também tem por intuito implementar uma proposta de política pública para a pixação e para o grafite na cidade. Nessa proposta, levam-se em consideração as noçôes do patrimônio, do urbanismo e da história. Para tanto, o Projeto Guernica trabalha com oficinas de formação de grafiteiros, debates em torno do Pa- trimônio Público, da História da Cidade e de práticas de cidadania.

13. Entrevista concedida por CRIPTA ao documentário Pixo, produzido pelos diretores João Weimar e Roberto T. Oliveira, lançado no mês de dezembro de 2009. Permito-me utilizar aqui a fala do pixador paulistano, pois CRIPTA é uma figura muito representativa, não só para a pixação mineira, e também pelo fato de que este mantém relaçôes de troca e alianças com pixadores e grupos mineiros.

14. A categoria nativa delega é utilizada pelos pixadores de modo pejorativo para designar a Delegacia de Polícia.

\section{Referências bibliográficas}

BECKER, Howard Saul. Outsiders. Rio de Janeiro: Jorge Zahar, 2008.

CAIAFA, Janice. O movimento punk na cidade. Rio de Janeiro: Jorge ZAHAR, 1987.

CARVALHO, Rodrigo Amaro de. Entre prezas e rolês: pixadores e pixações delem Belo Horizonte. Dissertação (Mestrado) - FAFICH - UFMG. Programa de Pós Graduação em Antropologia Social. Belo Horizonte, 2013.

GELL, Alfred. Definição do problema: a necessidade de uma antropologia da arte. In: Revista Poiésis, n. 14, p. 245-261, dez., 2009.

GUATTARI, Félix. Revolução molecular: pulsações politicas do desejo. São Paulo: Brasiliense, 1981.

GEERTZ, Clifford. O saber local: novos ensaios em antropologia interpretativa. Petrópolis, RJ: Vozes, 1997.

GOFFMAN, Erving. Estigma. 4a ed. Rio de Janeiro: Guanabara, 1988.

MAGNANI, José Guilherme Cantor, TORRES, Lílian de Lucca. (orgs.) Na metrópole: textos de antropologia urbana. São Paulo: EDUSP; Fapesp, 2008.

PEREIRA, Alexandre Barbosa. De rolê pela cidade. Dissertação (Mestrado). - Faculdade de Filosofia, Letras e Ciências Humanas, Universidade de São Paulo, São Paulo, 2005.

"Pichando a cidade: apropriações 'impróprias' do espaço urbano”. In: MAGNANI, José Guilherme Cantor, SOUZA, Bruna Mantese de. (org.) Jovens na metrópole: etnografias de circuitos de lazer, encontro e sociabilidade. $1^{\text {a }}$ ed. São Paulo: Editora Terceiro Nome, 2007. 
SOUZA, David da Costa. "Graffiti, Pichação e outras modalidades de intervençáo urbana: caminhos e destinos da arte de rua brasileira". In: ENFOQUES, v. 7 , n. 1 (Março de 2008). Rio de Janeiro: PPGSA, 2008. Acesso em 15 de outubro de 2012.
STRATHERN, Marilyn. Kinship, Law and the Unexpected: Relatives are Always a Surprise. Cambridge: Cambridge University Press, 2005.

\section{autor Rodrigo Amaro de Carvalho}

Doutorando em Antropologia Social / Museu Nacional-UFRJ

Recebido em 10/11/2013

Aceito para publicação em 16/12/2013 